\title{
IDENTIFIKASI MORFOMETRI EKSUVIA TONGGERET DI KEBUN RAYA BOGOR
}

\section{MORPHOMETRICS IDENTIFICATION OF CICADA EXUVIAE IN BOGOR BOTANICAL GARDENS}

\author{
Anang Setyo Budi, Encilia, Agmal Qodri \\ Museum Zoologicum Bogoriense, Pusat Penelitian Biologi-LIPI \\ Gedung Widyasatwaloka, Jl. Raya Bogor KM. 46, Cibinong, Bogor, Jawa Barat \\ E-mail: anangsetyobudi@gmail.com
}

(diterima Juli 2020, direvisi September 2020, disetujui Desember 2020)

\begin{abstract}
ABSTRAK
Tonggeret (Hemiptera: Cicadidae) sebagian besar daur hidupnya berada di dalam tanah, dengan nimfa yang akan muncul ke permukaan saat memasuki fase dewasa. Dalam proses metamorfosis menjadi dewasa, tonggeret akan melepaskan kulit terluarnya yang disebut dengan eksuvia. Tujuan penelitian ini adalah untuk melakukan identifikasi spesies tonggeret yang ada di Kebun Raya Bogor berdasarkan eksuvianya. Tercatat ada tiga spesies tonggeret berdasarkan identifikasi eksuvia yang ditemukan di Kebun Raya Bogor yaitu Chremistica pontianaka, Dundubia vaginata, dan Cryptotympana acuta. Dari hasil analisis menunjukkan terdapat perbedaan morfometri yang signifikan dari ketiga spesies tersebut, sehingga dapat digunakan sebagai pembeda antar spesies. Kunci identifikasi berdasarkan morfometri eksuvia tonggeret juga dibuat untuk memudahkan identifikasi tonggeret di Kebun Raya Bogor.
\end{abstract}

Kata kunci: Identifikasi, morfometri, eksuvia tonggeret, Kebun Raya Bogor.

\begin{abstract}
Cicadas (Hemiptera: Cicadidae) are insect that spend most of their lifetime underground, with the nymphs remain in the soil until they emerge as adults. In the process of metamorphosis into adults, cicadas will release its outer skin called exuviae. The purpose of this study was to identify the species of cicadas in the Bogor Botanical Gardens based on exuviae. There are three species recorded based on exuviae collected in Bogor Botanical Gardens is Chremistica pontianaka, Dundubia vaginata, and Cryptotympana acuta. The analysis indicated significant morphometric differences between species, thus could be used for identification to the species level. An identification key based on morphometrics of cicada exuviae are provided.
\end{abstract}

Keywords: Morphometrics, identification, cicada exuviae, Bogor Botanical Gardens.

\section{PENDAHULUAN}

Tonggeret hidup dalam fase nimfa selama satu sampai 17 tahun (Lee 2005; Lee $e t$ al. 2012; Williams dan Simon 1995). Dalam fase nimfa instar pertama hingga terakhir, tonggeret berada di dalam tanah (Boulard 1965; Logan 2006). Nimfa tonggeret mengambil nutrisi dari xilem akar tumbuhan hingga dapat menyebabkan kerusakan pada tumbuhan inangnya tersebut (White \& Strehl 1978). Menurut Darko \& Eltahir (2012), nimfa tonggeret akan muncul ke permukaan tanah dan merayap menuju batang atau ranting pohon terdekat untuk melakukan metamorfosis menjadi fase dewasa. Individu tonggeret akan melakukan molting saat malam hari untuk mengurangi resiko serangan predator. Setelah proses molting, tonggeret dewasa hanya dapat hidup selama dua hingga enam minggu (Beamer 1928).

Eksuvia adalah kulit atau cangkang yang dilepaskan saat proses molting pada hewan. Cangkang tersebut dapat ditemui menempel di batang atau ranting pohon (Grimaldi et al. 2005). Eksuvia dapat bertahan dalam kondisi bagus hingga beberapa minggu jika tidak diterpa angin kencang atau hujan (Pons 2015). Pada kondisi tertentu, eksuvia sering digunakan untuk membantu proses identifikasi jenis. Beberapa penelitian telah 
menunjukkan bahwa eksuvia dari fase akhir nimfa dapat digunakan untuk proses identifikasi hingga tingkat spesies (Boulard 1965; Ellingson et al. 2002; Hayashi 1976; Pachas 1966; Maccagnan \& Martinelli 2011; Williams \& Simon 1995). Tonggeret dewasa dapat terbang dan sering kali berada di batang atau ranting pohon yang tinggi. Kondisi tersebut sering kali menyulitkan dalam melakukan koleksi dan identifikasi tonggeret. Eksuvia tonggeret lebih mudah untuk dikoleksi karena berada di batang atau ranting pohon bagian bawah dan akar pohon (Lee et al. 2012).

Kebun Raya Bogor merupakan lembaga konservasi ex situ yang melakukan fungsi konservasi tumbuhan tropis. Sebagai kawasan perlindungan plasma nutfah dengan koleksi tumbuhan yang cukup lengkap, Kebun Raya Bogor menjadi salah satu habitat tonggeret di Indonesia. Dari hasil penelitian terdahulu yang dilakukan oleh Anggradewi (2008) dan Sofyan dkk. (2016), terdapat dua jenis tonggeret yang hidup di kawasan Kebun Raya Bogor. Metode yang digunakan dalam penelitian tersebut adalah bioakustik dengan melakukan identifikasi rekaman suara dan identifikasi morfologi secara langsung hasil koleksi. Dari kedua jenis tonggeret yang ditemukan hanya satu yang dapat diidentifikasi hingga tingkat spesies, yaitu Dundubia vaginata. Kesulitan dalam proses koleksi individu dan masih sedikitnya data suara tonggeret menjadi faktor penghambat dalam identifikasi menggunakan metode rekaman suara.

Identifikasi tonggeret dengan menggunakan eksuvia merupakan salah satu metode yang efisien (Lee et al. 2012). Penggunaan eksuvia juga sangat bermanfaat untuk melakukan estimasi populasi tonggeret (Cook et al., 2001; Karban, 1982, 1984, 1985; Mac Nally \& Doolan,
1986; Oberdorster \& Grant, 2006; Takakura \& Yamazaki, 2007; White et al., 1979; Young, 1980; ). Metode morfometri eksuvia untuk identifikasi tonggeret belum pernah dilakukan di Indonesia. Penelitian kali ini bertujuan untuk melakukan identifikasi tonggeret yang ada di Kebun Raya Bogor dengan menggunakan metode morfometri pada eksuvia yang ditemukan. Kunci identifikasi berdasarkan eksuvia yang ditemukan juga dibuat untuk memudahkan identifikasi tonggeret di Kebun Raya Bogor.

\section{METODE PENELITIAN}

Pengambilan sampel eksuvia tonggeret dilakukan sebanyak empat kali pada bulan Maret 2020 di kawasan Kebun Raya Bogor. Proses koleksi sampel eksuvia dilakukan pada pukul 18.00 - 20.00 WIB. Eksuvia dikoleksi dari batang, ranting, dan akar pohon di sisi kiri dan kanan sepanjang jalur pejalan kaki. Setiap pohon yang menjadi tempat eksuvia menempel dicatat dan diberi tanda sebagai titik lokasi koleksi nimfa tingkat akhir. Proses koleksi nimfa tingkat akhir tonggeret dilakukan dengan mengambilnya dari batang pohon sebelum proses ganti kulit atau menggali tanah di sekitar pohon yang telah ditandai sebelumnya. Nimfa tingkat akhir tonggeret yang telah siap menuju fase dewasa dikoleksi dari pukul 21.00 -00.00 WIB. Hasil koleksi nimfa tingkat akhir kemudian dibedah dan dipisahkan dari eksuvianya. Koleksi sampel dan identifikasi morfologi nimfa tingkat akhir dilakukan untuk memastikan keakuratan identifikasi menggunakan eksuvia.

Dari hasil penelusuran lokasi eksuvia, ditentukan sebanyak 4 titik pengambilan sampel, yaitu (a) Pohon Aglaia odoratissima di blok III.C.58. area Kolam Gunting, (b) Pohon Syzygium sp. di blok VI.C.314. selatan makam Mbah Jepra, (c) Pohon Dalbergia sp. di blok 

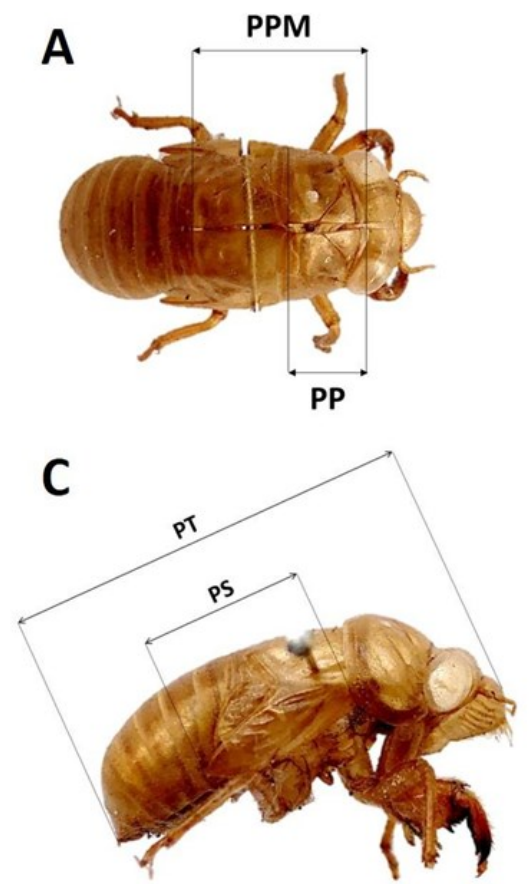

B

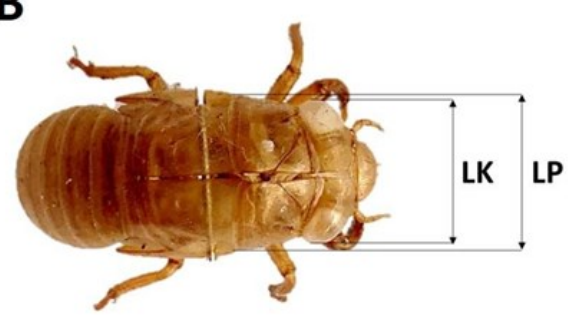

D

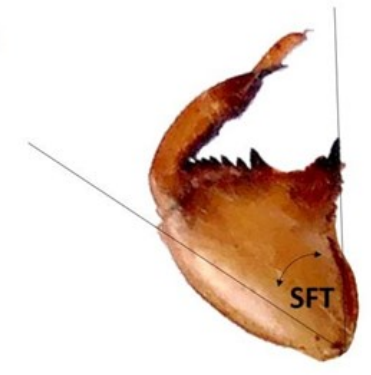

Gambar 1. Karakter morfologi eksuvia tonggeret yang diukur. PPM panjang pro-mesonotum; PP panjang pronotum; LP lebar pronotum; LK lebar kepala; PT panjang tubuh; PS panjang sayap; SFT sudut femoral tooth.

XVI.I.11.24., dan (d) Pohon Popowia pisocarpa di blok XVI.1.1.11 sebelah barat Grand Garden. Hasil koleksi eksuvia dan nimfa tingkat akhir dikelompokkan sesuai dengan titik pengambilan dan diberi nomor. Eksuvia dan nimfa tingkat akhir tonggeret dipreservasi di Laboratorium Biosistematika Serangga dan Arthropoda Lain, Bidang Zoologi, Pusat Penelitian Biologi-LIPI. Setelah dikeringkan, eksuvia dan nimfa tingkat akhir di-pinning dan disusun sesuai nomor. Nimfa tingkat akhir tonggeret diidentifikasi secara morfologi untuk mengetahui spesiesnya. Sampel dibandingkan dengan koleksi spesimen imago tonggeret Bidang Zoologi, Pusat Penelitian Biologi-LIPI. Pengamatan morfologi dilakukan dengan mikroskop Leica M50. Hasil identifikasi nimfa tingkat akhir tersebut digunakan untuk mendukung keakuratan metode morfometri eksuvia.

Eksuvia yang telah dipreservasi kemudian dipidahkan berdasarkan jenis kelamin dengan melihat morfologi genitalia pada bagian apex pada abdomen. Selanjutnya bagian dorsal, lateral, dan femur eksuvia difoto menggunakan kamera Olympus DP70 yang dipasang pada mikroskop Olympus SZX12. Pengukuran morfologi eksuvia dilakukan dengan menggunakan software ImageJ berdasarkan foto yang telah diambil sebelumnya. Karakter morfologi yang diukur adalah panjang pro-mesonotum, lebar pronotum, panjang pronotum, lebar kepala, panjang tubuh, panjang sayap, dan sudut femoral tooth (Gambar 1). Terminologi karakter yang digunakan mengacu pada Lee et al. (2012). Khusus untuk panjang tubuh, pengukuran dilakukan menggunakan kaliper. Analisis Multivariate Univariate General Linear Model (GLM) dan visualisasi dilakukan dengan menggunakan software $\mathrm{R}$ Studio 1.3 .959 (RStudio Team 2020) untuk menunjukkan perbedaan karakter morfologi berdasarkan spesies dan jenis kelamin. Kunci identifikasi dibuat berdasarkan hasil pengukuran dan analisis. 


\section{HASIL DAN PEMBAHASAN}

Hasil identifikasi morfologi nimfa tingkat akhir menunjukkan bahwa terdapat tiga spesies tonggeret dari tiga marga yang hidup di Kebun Raya Bogor. Spesies tonggeret yang ditemukan adalah Dundubia vaginata (Fabricius, 1787), Chremistica pontianaka Stål, 1870, dan Cryptotympana acuta (Signoret, 1849). D. vaginata memiliki persebaran dari China, India, Semenanjung Malaya, hingga kepulauan Sunda Besar (Overmeer \& Duffels 1967). Mengacu pada Sanborn (2013), Ch. pontianaka tersebar di Filipina, Malaysia, Singapura, dan Indonesia (Sumatra, Jawa, dan Kalimantan). Terdapat catatan yang menyatakan bahwa spesies tersebut juga dijumpai hingga Papua Nugini. Sementara itu, Cr. acuta memiliki persebaran yang hampir sama dengan $D$. vaginata. $C r$. acuta tersebar dari China, India, Semenanjung Malaya, Sumatra, hingga ke Timor (Price et al. 2016).

Ch. pontianaka menjadi spesies yang paling umum ditemukan di Kebun Raya Bogor, yang terdapat di dua lokasi (c) dan (d). D. vaginata ditemukan di titik (b) dan Cr. acuta ditemukan di titik (a). Menurut O'Geen dan Busacca (2001) nimfa tingkat akhir tonggeret banyak ditemui pada kedalaman 10-30 $\mathrm{cm}$ dari permukaan tanah tepatnya pada horizon A dan horizon B lapisan tanah. Pada penelitian ini, nimfa tingkat akhir banyak ditemukan di kedalaman 15-30 cm dari permukaan tanah. Jumlah nimfa tingkat akhir tonggeret yang ditemukan sebanyak sembilan individu, terdiri dari enam individu Ch. pontianaka $(2 \widehat{\jmath}, 4$ ) $)$, dua individu betina D. vaginata, dan satu individu jantan Cr. acuta. Terdapat dua individu nimfa tingkat akhir Ch. pontianaka yang dikoleksi langsung dengan tangan karena berada di batang pohon bagian bawah saat proses molting. Tingkatan pada nimfa tonggeret dapat dilihat dari perkembangan morfologi pada bagian mata dan sayap. Terbentuknya kapsul bulat di bagian mata dan tumbuhnya tunas sayap menandakan bahwa nimfa telah memasuki tingkat akhir (Hou et al. 2014).

Eksuvia yang berhasil dikoleksi sebanyak 79 buah tersebar di empat titik pengambilan sampel. Pengambilan sampel eksuvia di setiap lokasi dilakukan di satu pohon yang sama, termasuk juga pengambilan sampel nimfa tingkat akhir. Dari seluruh sampel tersebut, diambil 36 sampel eksuvia dengan kondisi paling baik yang terdiri atas masing-masing 12 sampel dari tiga lokasi (Gambar 2).
A

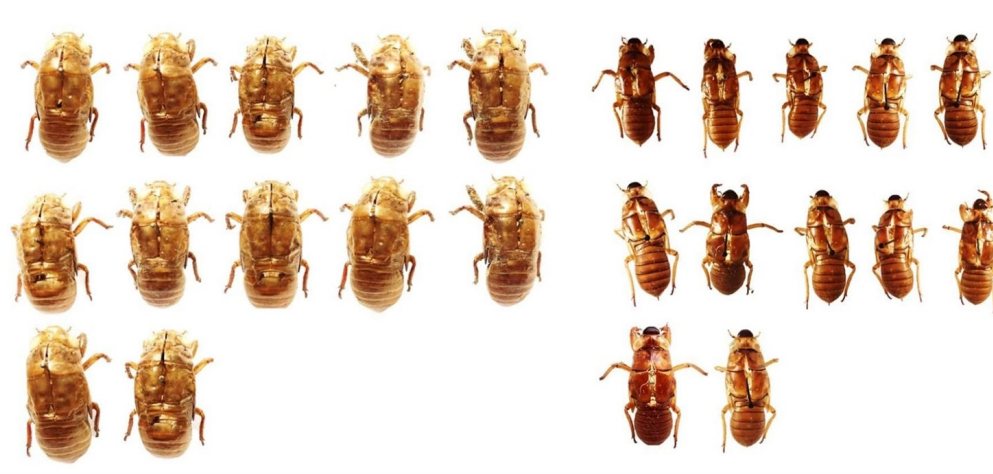

C

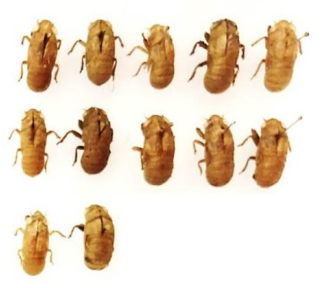

$20 \mathrm{~mm}$

Gambar 2. Sampel eksuvia tonggeret hasil koleksi (A: titik (a) Cr. acuta, B: titik (b) D. vaginata, C: titik (c) C. pontianaka). 


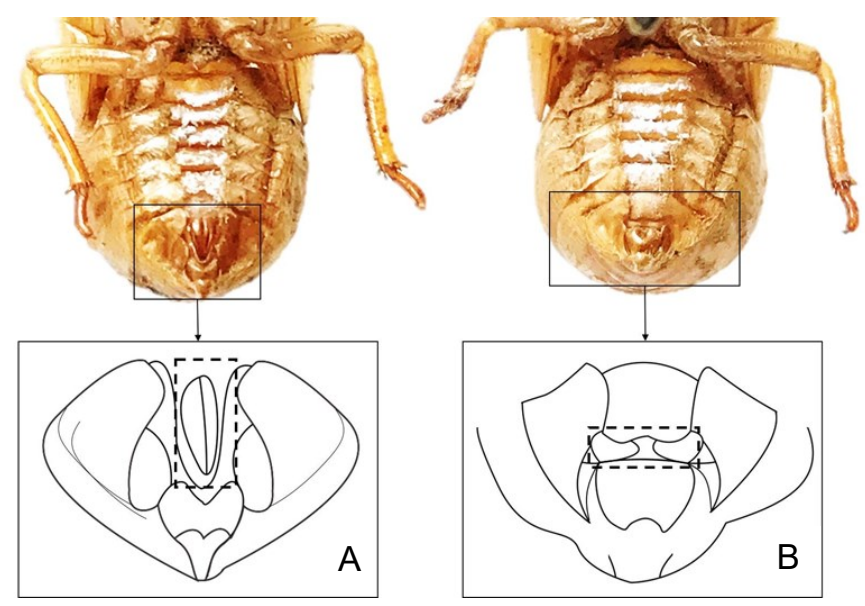

Gambar 3. Perbedaan antara Ch. pontianaka betina (A) dan jantan (B) berdasarkan morfologi genitalia pada apex abdomen eksuvia.

Sampel dari lokasi (d) tidak dimasukkan untuk analisis data selanjutnya karena hasil identifikasi nimfa tingkat akhir menunjukkan bahwa pada lokasi (c) dan (d) hanya terdapat satu spesies, yaitu Ch. pontianaka. Sebanyak 12 sampel dari tiap lokasi terdiri atas enam eksuvia jantan dan enam eksuvia betina. Perbedaan antara eksuvia jantan dan betina terletak pada bagian apex abdomen (Lee et al.
2012). Pada eksuvia tonggeret betina terdapat dua tonjolan posterior marginal khas yang mirip dengan ovipositor tonggeret betina dewasa. Untuk eksuvia tonggeret jantan, terdapat tonjolan dengan bentuk bervariasi pada setiap spesies namun ukurannya lebih kecil dari tonjolan pada betina. Sebagai contoh, pada Ch. pontianaka jantan terdapat dua tonjolan dengan bentuk bulat telur pada bagian apex abdomen (Gambar 3).

Tabel 1. Hasil analisis univariate GLM karakter morfologi eksuvia tonggeret.

\begin{tabular}{llllll}
\hline Source & Dependent Variable & df & Mean Square & F & P Value \\
\hline Spesies & PPM & 2 & 145.726 & 1414.732 & $<0.001$ \\
& LP & 2 & 95.383 & 479.843 & $<0.001$ \\
& PP & 2 & 24.876 & 211.876 & $<0.001$ \\
& LK & 2 & 73.995 & 601.849 & $<0.001$ \\
& PT & 2 & 752.043 & 1306.414 & $<0.001$ \\
& PS & 2 & 137.875 & 512.967 & $<0.001$ \\
\multirow{5}{*}{ Jenis Kelamin } & SFT & 2 & 256.690 & 91.831 & $<0.001$ \\
& PPM & 1 & 0.460 & 4.468 & 0.041 \\
& LP & 1 & 1.050 & 5.283 & 0.027 \\
& PP & 1 & 2.385 & 20.315 & $<0.001$ \\
& LK & 1 & 5.535 & 45.021 & $<0.001$ \\
& PT & 1 & 4.687 & 8.143 & 0.007 \\
Error & PS & 1 & 4.260 & 15.850 & $<0.001$ \\
& SFT & 1 & 1.021 & 0.365 & 0.549 \\
& PPM & 42 & 0.103 & & \\
& LP & 42 & 0.199 & & \\
& PP & 42 & 0.117 & & \\
& LK & 42 & 0.123 & & \\
\hline
\end{tabular}


Hasil dari analisis multivariate GLM menunjukkan bahwa pengaruh faktor spesies (Wilks' $\lambda=0, \mathrm{~F}=447.449$, hypothesis $\mathrm{df}=14.000$, error $\mathrm{df}=72.000, \quad \mathrm{P}=0$ ) dan faktor jenis kelamin (Wilks' $\lambda=0.175, \mathrm{~F}=24.181$, hypothesis $\mathrm{df}=7.000$, error $\mathrm{df}=36.000, \mathrm{P}=0$ ) adalah signifikan. Berdasarkan hasil analisis univariate GLM, spesies dan jenis kelamin merupakan faktor yang berpengaruh signifikan terhadap karakter morfometri eksuvia tonggeret yang diukur kecuali pada sudut femoral tooth
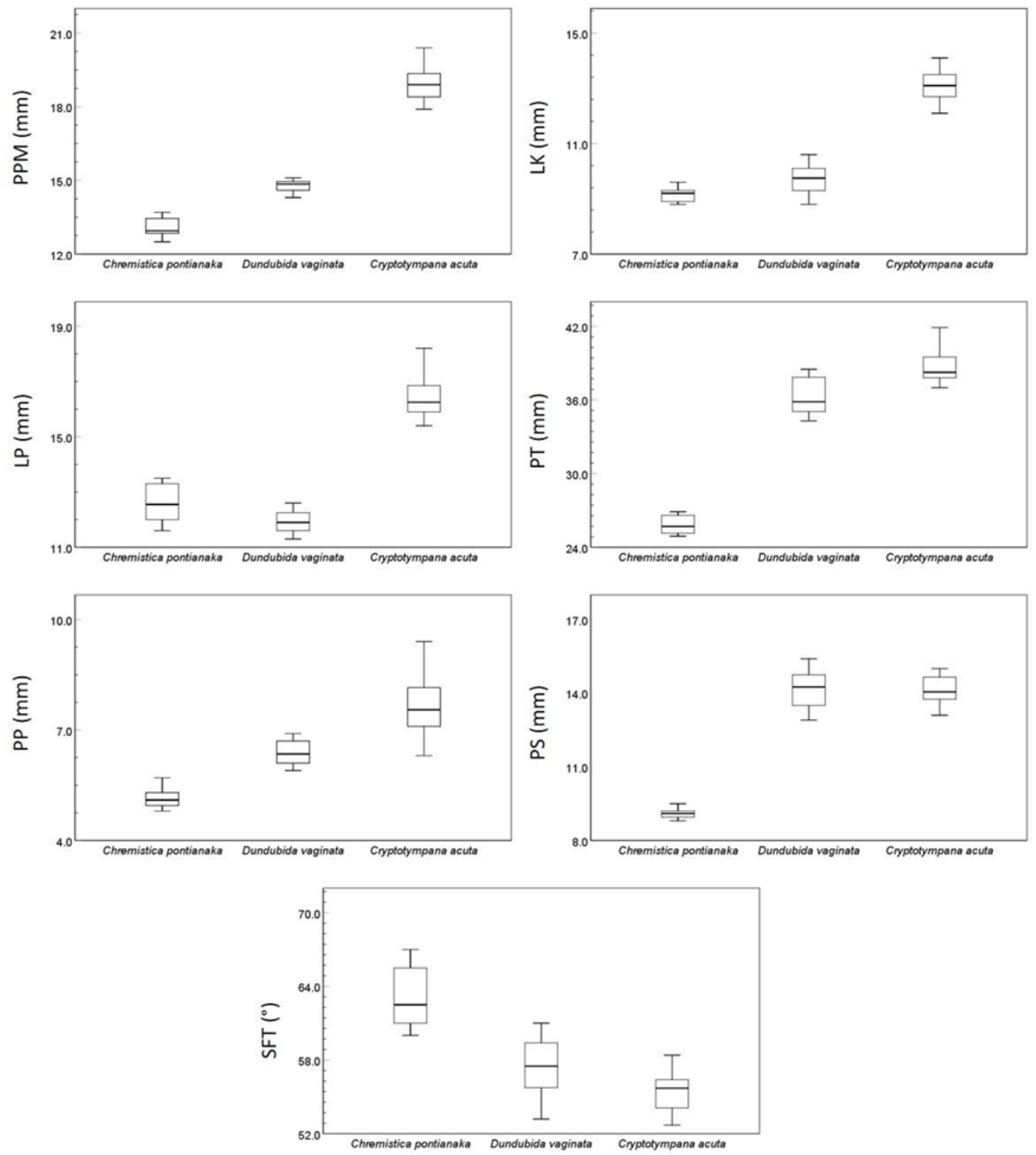

Gambar 4. Distribusi karakter morfologi eksuvia tonggeret di Kebun Raya Bogor (A: panjang pro-mesonotum, B: lebar pronotum, C: panjang pronotum, D: lebar kepala, E: panjang tubuh, F: panjang sayap, G: sudut femoral tooth. 
kecuali sudut femoral tooth. Hasil pengukuran PPM, LP, dan LK menunjukkan $C r$. acuta memiliki nilai paling besar pada setiap karakter tersebut (Gambar 4A,4B,4D). Karakter tersebut efektif digunakan sebagai pembeda antara $C r$. acuta dan dua spesies lainnya karena rentang selisih nilainya cukup besar. Karakter PT menjadi pembeda paling efektif antara Ch. pontianaka dengan dua spesies lainnya karena memiliki rentang selisih ukuran yang cukup besar (Gambar 4E). Ukuran PS Cr. acuta dan D. vaginata hampir sama, sehingga sulit untuk membedakan keduanya dengan karakter tersebut (Gambar 4F). SFT juga tidak efektif untuk digunakan sebagai karakter pembeda antara $\mathrm{Cr}$. acuta dan $D$. vaginata karena perbedaan rentang nilainya tidak terlalu besar (Gambar 4G).

Berdasarkan hasil pengukuran dan analisis di atas dapat ditentukan kunci identifikasi eksuvia tonggeret di Kebun Raya Bogor adalah sebagai berikut:

1. a. Panjang tubuh $<26,9 \mathrm{~mm}$..........2

1. b. Panjang tubuh $>26,9 \mathrm{~mm}$........... 3

2. Eksuvia berwarna coklat muda mengilap; femur comb dan protibia pada kaki depan berwarna hitam; sternite berwarna abu-abu cerah; pada jantan lebar pronotum $>13 \mathrm{~mm}$, tonjolan pada apex abdomen berbentuk bulat telur pada kedua sisi; pada betina lebar pronotum $<13 \mathrm{~mm}$, tonjolan pada apex abdomen menyerupai bentuk ovipositor tonggeret betina dewasa Ch. pontianaka

3. a. Panjang pro-mesonotum $>17,9 \mathrm{~mm}$; seluruh bagian clypeus berwarna coklat terang, garis antar tergite terlihat samar; abdomen oval melebar; femur comb dan tibia pada kaki depan berwarna hitam; pada jantan lebar kepala $>31,1 \mathrm{~mm}$, tonjolan pada apex abdomen berbentuk setengah ling karan pada kedua sisi; pada betina lebar kepala $<31,1 \mathrm{~mm}$, tonjolan pada apex abdomen menyerupai bentuk ovipositor tonggeret betina dewasa .Cr. acuta

3. b. Panjang pro-mesonotum $<17,9 \mathrm{~mm}$; bagian atas clypeus berwarna hitam; garis antar tergite tampak jelas berwarna coklat gelap; abdomen oval memanjang; femur comb dan apical tooth tibia berwarna hitam; pada jantan sudut femoral tooth $<57,3^{\circ}$, tonjolan pada apex abdomen berbentuk lingkaran di bagian tengah dan setengah lingkaran pada kedua sisi; pada betina sudut femoral tooth $>57,3^{\circ}$, tonjolan pada apex abdomen menyerupai bentuk ovipositor tonggeret betina dewasa D. vaginata

\section{KESIMPULAN}

Perbedaan karakter morfologi berdasarkan hasil pengukuran eksuvia dapat digunakan untuk melakukan identifikasi jenis tonggeret di Kebun Raya Bogor. Terdapat tiga spesies tonggeret yang ditemukan, yaitu Chremistica pontianaka, Dundubia vaginata, dan Cryptotympana acuta. Hasil analisis morfometri menunjukkan bahwa setidaknya terdapat satu karakter eksuvia yang dapat secara jelas menunjukkan perbedaan antar genus. Hal tersebut membuktikan bahwa metode morfometri eksuvia efektif digunakan untuk melakukan identifikasi jenis tonggeret di Kebun Raya Bogor. Metode tersebut dapat mempermudah identifikasi jenis tonggeret tanpa harus mengalami kesulitan dalam koleksi imago. Untuk penelitian selanjutnya, 
perlu dilakukan penambahan karakter morfologi yang diukur apabila terdapat dua spesies atau lebih dalam satu genus yang sulit dibedakan.

\section{UCAPAN TERIMA KASIH}

Ucapan terima kasih disampaikan kepada Dr. Cahyo Rahmadi selaku Kepala Bidang Zoologi, Pusat Penelitian Biologi - LIPI atas dukungan dan izin penelitian yang telah diberikan. Dr. R. Hendrian, M.Sc. selaku Kepala Pusat Penelitian Konservasi Tumbuhan dan Kebun Raya - LIPI atas diberikannya izin penelitian di wilayah Kebun Raya Bogor. Tim Peneliti dari Bidang Zoologi (Fajrin Shidiq, Alamsyah Elang, Endah Dwijayanti, Syahfitri Anita, Gloria Animalesto, Syahfitri Anita) dan P2KTKR (Enggal Primananda, Dipta Sumeru) yang turut membantu selama pengambilan sampel di lapangan.

\section{DAFTAR PUSTAKA}

Anggradewi, A. (2008). Identifikasi Tonggeret (Hemiptera Cicadidae) di Kebun Raya Bogor dan Kebun Raya Cibodas Berdasarkan Rekaman Suara. Skripsi. Bogor: Institut Pertanian Bogor.

Beamer, R. H. (1928). Studies on the biology of Kansas Cicadidae. University of Kansas Science Bulletin, 18, 155-263.

Boulard, M. (1965). Notes sur la biologie larvaire de las cigales (Hom. Cicadidae). Annales de la Société entomologique de France, 1(3), 503-521.

Cook, W. M., Holt, R. D. \& Yao, J. (2001). Spatial variability in oviposition damage by periodical cicadas in a fragmented landscape. Oecologia, 127, 51-61.

Darko, N. Y., Eltahir, N. (2012). Host Selectivity by Cicada for Final Stage of Moulting. Sudan Journal of Science, 5, 1-8.
Ellingson, A. R., Andersen, D. C., Kondratieff, B. C. (2002). Observations of the larval stages of Diceroprocta apache Davis (Homoptera: Tibicinidae). Journal of The Kansas Entomological Society, 75, 283-289.

Grimaldi, D., Engel, M. S. (2005). Evolution of the Insects. Cambridge: Cambridge University Press.

Hayashi, M. (1976). Description of the nymphs of Mogannia minuta Matsumura (Homoptera: Cicadidae), pest of sugarcane in the Ryukyus. Kontyû, 44, 142-149.

Hou, Z., Li, Q. \& Wei, C. (2014). Morphology and identification of the final instar nymphs of three cicadas (Hemiptera, Cicadidae) in Guanzhong Plain, China based on comparative morphometrics. Zookeys, 425, 33-50.

Karban, R. (1982). Increased reproductive success at high densities and predator satiation for periodical cicada. Ecology, 63, 321-328.

Karban, R. (1984). Opposite density effects of nymphal and adult mortality for periodical cicadas. Ecology, 65, 16561661.

Karban, R. (1985). Addition of periodical cicada nymphs to an oak forest, effects on cicada density, acorn production, and rootlet density. Journal of The Kansas Entomological Society, 58, 269-276.

Lee, H. Y., Oh, S. Y. \& Jang, Y. (2012). Morphometrics of the final instar exuviae of five cicada species occurring in urban areas of central Korea. Journal of AsiaPacific Entomology, 15, 627-630.

Lee, Y. J. (2005). Cicada of Korea. Seoul: Geobook.

Logan, D. (2006). Nymphal development and lifecycle length of Kikihia ochrina 
(Walker) (Homoptera: Cicadidae). Weta, 31, 19-22.

Mac Nally, R. C. \& Doolan, J. M. (1986). Patterns of morphology and behaviour in a cicada guild: a neutral model analysis. Australian Journal of Ecology, 11, 279-294.

Maccagnan, D. H. B. \& Martinelli, N. M. (2011). Description and key to the fifthinstars of some Cicadas (Hemiptera: Cicadidae) associated with coffee plants in Brazil. Neotropical Entomology, 40 (4), 445-51.

O'Geen, A. T., Busacca, A. J. (2001) Faunal burrows as indicators of paleovegetation in eastern Washington, USA. Palaeogeography, Palaeoclimatology, Palaeoecology, 169, 23-37.

Oberdorster, U., Grant, P. R. (2006). Predicting emergence, chorusing, and oviposition of periodical cicadas. Ecology, 87, 409418.

Overmeer, W. P. J., Duffels, J. P. (1967). A revisionary study of the genus Dundubia Amyot \& Serville (Homoptera, Cicadidae). Beaufortia, 166, 9-59.

Pachas, P. O. (1966). La chicharra de la yerba mate (Fidicina mannifera, Fab., 1803) su biología e observaciones sobre los métodos de control en Misiones (República Argentina). Idia, 217, 5-15.

Pons, P. (2015). Delayed effects of fire and logging on cicada nymph abundance. Journal of Insect Conservation, 19(3), 601-606.

Price, B. W., Allan, E. L., Marathe, K., Sarkar, V., Simon, C., Kunte, K. 2016. The cicadas (Hemiptera: Cicadidae) of India, Bangladesh, Bhutan, Myanmar, Nepal and Sri Lanka: an annotated provisional catalogue, regional checklist and bibliography. Biodiversity Data Journal, 4, e8051.

RStudio Team (2020). RStudio: Integrated Development for R. RStudio, PBC, Boston, MA URL http://www.rstudio.com/.

Sanborn, A. F. 2013. Catalogue of Cicadoidea (Hemiptera: Auchenorrhyncha). New York: Academic Press.

Sofyan, F., Raffiudin, R. \& Hidayat, P. (2016). Karakteristik Bioakustik Tonggeret (Hemiptera : Cicadidae) Di Kebun Raya Bogor. Skripsi. Bogor: Institut Pertanian Bogor.

Takakura, K. I., Yamazaki, K. (2007). Cover dependence of predation avoidance alters the effect of habitat fragmentation on two cicadas (Hemiptera: Cicadidae). Annals of the Entomological Society of America, 100, 729-735.

White, J. \& Strehl, C. E. (1978). Xylem feeding by periodical cicada nymphs on tree roots. Ecological Entomology, 3(4), 323-327.

White, J., Lloyd, M. \& Zar, J. H. (1979). Faulty eclosion in crowded suburban periodical cicadas: populations out of control. Ecology, 60, 305-315.

Williams, K. S., \& Simon, C. (1995). The Ecology, Behavior, and Evolution of Periodical Cicadas. Annual Review of Entomology, 40, 269-295.

Young, A. M. (1980). Habitat and seasonal relationships of some cicadas (Homoptera: Cicadidae) in central Costa Rica. The American Midland Naturalist, 103, 155-166. 